\title{
The association of posttraumatic stress disorder and metabolic syndrome: a study of increased health risk in veterans Pia S Heppner*1,2, Eric F Crawford ${ }^{3}$, Uzair A Haji ${ }^{1}$, Niloofar Afari1,2, Richard L Hauger ${ }^{1,2}$, Boris A Dashevsky ${ }^{4}$, Paul S Horn ${ }^{4,5}$, Sarah E Nunnink ${ }^{1}$ and Dewleen G Baker ${ }^{1,2}$
}

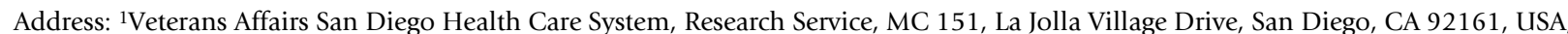
${ }^{2}$ Department of Psychiatry, University of California at San Diego, Gilman Drive, MC:0603, La Jolla, CA 92093-0603, USA, ${ }^{3}$ Durham Veterans Affairs Medical Center, Felton Street, Durham, NC 27705, USA, ${ }^{4}$ Psychiatry Service, Cincinnati Veterans Affairs Medical Center, Vine Street, Cincinnati, OH 45220, USA and ${ }^{5}$ Department of Mathematical Sciences, University of Cincinnati, Old Chemistry Building, Cincinnati, OH 45221 0025, USA

Email: Pia S Heppner* - pheppner@ucsd.edu; Eric F Crawford - Eric.Crawford@va.gov; Uzair A Haji - uzair.haji2@va.gov; Niloofar Afari - nafari@ucsd.edu; Richard L Hauger - rhauger@ucsd.edu; Boris A Dashevsky - boris_dashevsky@hotmail.com; Paul S Horn - paul.horn@uc.edu; Sarah E Nunnink - sarah.nunnink@va.gov; Dewleen G Baker - dgbaker@ucsd.edu

* Corresponding author
\end{abstract}

Published: 9 january 2009

BMC Medicine 2009, 7:I doi:10.1186/1741-7015-7-1
Received: 6 November 2008

Accepted: 9 January 2009

This article is available from: http://www.biomedcentral.com/I74|-70I5/7/I

(c) 2009 Heppner et al; licensee BioMed Central Ltd.

This is an Open Access article distributed under the terms of the Creative Commons Attribution License (http://creativecommons.org/licenses/by/2.0), which permits unrestricted use, distribution, and reproduction in any medium, provided the original work is properly cited.

\begin{abstract}
Background: There is accumulating evidence for a link between trauma exposure, posttraumatic stress disorder (PTSD) and diminished health status. To assess PTSD-related biological burden, we measured biological factors that comprise metabolic syndrome, an important established predictor of morbidity and mortality, as a correlate of long-term health risk in PTSD.

Methods: We analyzed clinical data from 253 male and female veterans, corresponding to five factors linked to metabolic syndrome (systolic and diastolic blood pressure, waist-to-hip ratio and fasting measures of high-density lipoprotein (HDL) cholesterol, serum triglycerides and plasma glucose concentration). Clinical cut-offs were defined for each biological parameter based on recommendations from the World Health Organization and the National Cholesterol Education Program. Controlling for relevant variables including sociodemographic variables, alcohol/ substance/nicotine use and depression, we examined the impact of PTSD on metabolic syndrome using a logistic regression model.
\end{abstract}

Results: Two-fifths (40\%) of the sample met criteria for metabolic syndrome. Of those with PTSD $(n=139), 43 \%$ met criteria for metabolic syndrome. The model predicted metabolic syndrome well $(-2 \log$ likelihood $=316.650$, chi-squared $=23.73 \mathrm{I}, p=0.005)$. Veterans with higher severity of PTSD were more likely to meet diagnostic criteria for metabolic syndrome (Wald $=4.76, p=0.03$ ).

Conclusion: These findings provide preliminary evidence linking higher severity of PTSD with risk factors for diminished health and increased morbidity, as represented by metabolic syndrome. 


\section{Background}

Several lines of research suggest that stress and post-stress adaptational responses are related to long-term health outcomes. Studies of survivors of disasters, veterans and prisoners of war, and others exposed to severe trauma, suggest higher rates of physical morbidity and mortality and increased healthcare utilization related to lifetime prevalence of trauma [1-7]. There is accumulating evidence from epidemiological studies that chronic posttraumatic stress disorder (PTSD) may moderate the link between trauma and secondary negative health outcomes such as cardiovascular, metabolic and autoimmune conditions [4-9]. Furthermore, Chrousos and colleagues have linked maladaptive neuro-endocrine-immune responses to psychiatric, endocrine and/or autoimmune disease or vulnerability to such diseases $[10,11]$. Evidence for neuroendocrine-immune abnormalities associated with PTSD, also provides a biological rationale for downstream health effects observed in the epidemiological studies [12$16]$.

Metabolic syndrome or syndrome $\times$ is composed of a cluster of clinical signs including dyslipidemia, hyperglycemia (insulin resistance), central obesity and hypertension [17]. Recent research on the impact of stress on health has focused on metabolic syndrome as a possible consequence of pathophysiological adaptations to chronic stress [18]. Brunner and colleagues studied metabolic syndrome status in the Whitehall II cohort and found markers associated with increased stress-related neuroendocrine and autonomic activation such as lowered heart rate variability, increased cortisol output and higher levels of IL-6, C-reactive protein and blood viscosity among cases with metabolic syndrome as compared with those who did not meet diagnostic criteria [19]. Additional analyses of prospective data from the Whitehall cohort also suggest a dose-response relationship between stress and the presence of metabolic syndrome such that participants with chronic exposure to work stress were found to be more than twice as likely to have the syndrome after controlling for age, sex and health behaviors [20]. In a recent study of 2189 Gulf War I veterans, those with chronic multisymptom illness, as defined by presence of fatigue, musculoskeletal pain, mood or cognitive abnormalities for at least 6 months, had significantly higher prevalence of metabolic syndrome [21].

While there is a lack of consensus in specific clinical definitions of metabolic syndrome, prospective studies have shown it to be an important predictor of physical morbidity and mortality [22-25]. For example, in a comparison of four definitions based on guidelines from the World Health Organization (WHO) and the National Cholesterol Education Program (NCEP), metabolic syndrome was found to predict incidence and prevalence of diabetes mellitus in a prospective study [24]. Similarly, in a sample of 5128 men, metabolic syndrome was found to be a significant predictor of the development of cardiovascular disease (CVD) and diabetes mellitus [25].

In this study, we examined physical measures and laboratory values in a sample of veterans, to examine the association between PTSD severity and the presence of metabolic syndrome. We hypothesized that greater severity of PTSD would be associated with a higher likelihood of metabolic syndrome.

\section{Methods \\ Participants}

Comprehensive medical and mental health examinations were completed by 355 veterans entering Gulf War Screening and PTSD Programs at the Cincinnati Veterans Affairs, of whom 341 signed informed consents permitting use of their data for a health-related study. The study was conducted in accordance with the Helsinki Declaration, and was approved by the Institutional Review Board of the University of Cincinnati Medical Center and the Research Committee of the Cincinnati Veterans Affairs Medical Center (Protocol \#00-03-07-01-E; "Healthrelated quality of life in post-deployment veterans").

Of the 341 veterans with signed consent, we excluded 68 veterans who had missing data from at least one of the variables of interest, 18 veterans whose laboratory values were greater than 3 standard deviations (SD) from the group mean, and 2 veterans who had both missing data and laboratory values greater than 3 SD from the mean. Cases with extreme laboratory values were excluded to allow for a more conservative analysis of quantitative physiological burden. These exclusions yielded a remaining sample size of 253 veterans.

\section{Measures}

\section{Sociodemographics}

Veterans provided sociodemographic information including years of education, military service and deployment history via written questionnaires.

\section{Psychiatric diagnoses}

PTSD severity was measured using the Clinician Administered PTSD Scale (CAPS), which ranges in scores from 0 to 136 (see [26]). A score of 65 or above on the CAPS has been shown to be optimally specific and efficient in predicting PTSD and was used, along with the Diagnostic and Statistical Manual of Mental Disorders, 4th Edition (DSM-IV) criteria, to identify veterans with PTSD [27]. Lifetime and current diagnoses of major depressive disorder (MDD), substance, alcohol and nicotine abuse or dependence were determined using a structured diagnostic interview [28,29]. 


\section{Physical measures}

Physical examinations including waist-to-hip ratio (WHR), blood pressure and laboratory tests (12-hour fasting lipids, glucose) were conducted on each veteran. Phlebotomy was scheduled between 7 and 9 AM. All samples were assayed within the hospital clinical laboratory.

\section{Procedure}

In the context of a cross-sectional study, metabolic syndrome status was determined based on the clinical criteria for each factor outlined in Table 1. Systolic and diastolic blood pressure values were combined to represent one condition (hypertension as represented by systolic blood pressure (SBP) $\geq 130 \mathrm{~mm} / \mathrm{Hg}$ and diastolic blood pressure $(\mathrm{DBP}) \geq 85 \mathrm{~mm} / \mathrm{Hg}$ ) yielding a total of five criteria that contributed to metabolic syndrome. While the cut-off for elevated serum triglycerides was based on NCEP criteria, increased blood pressure, high-density lipoprotein (HDL), WHR and plasma glucose concentration were based on a modified set of criterion scores recommended by the WHO and the NCEP, similar to those used by Lakka and colleagues to evaluate CVD-related mortality and metabolic syndrome [23,30-32].

\section{Statistical analyses}

We examined the relationship between PTSD and metabolic syndrome using a logistic regression model. In addition, we conducted a series of independent-sample $t$-tests to determine whether those with PTSD differed on these five criteria from those without PTSD. Statistical analyses were conducted using SPSS (Statistical Package for Social Sciences) version 15.0. Metabolic syndrome was regressed on the following predictors: PTSD severity (CAPS), age, gender, race (white, black/other), years of education, history of substance abuse/dependence, history of alcohol abuse/dependence, nicotine abuse/dependence (lifetime) and current or past diagnosis of MDD. All predictors were simultaneously entered into the regression model as a sin-

Table I: Clinically determined criterion scores for metabolic syndrome

\begin{tabular}{ll}
\hline Measures & Criterion score \\
\hline Serum triglycerides & $\geq 150 \mathrm{mg} \mathrm{dl}-1$ \\
High-density lipoprotein & $<35 \mathrm{mg} \mathrm{dl}^{-1}$ \\
Blood pressurea & \\
$\quad$ Systolic & $\geq 130 \mathrm{~mm} / \mathrm{Hg}$ \\
$\quad$ Diastolic & $\geq 85 \mathrm{~mm} / \mathrm{Hg}$ \\
Waist-to-hip ratio & $\geq 0.90$ \\
$\quad$ Men & $\geq 0.85$ \\
$\quad$ Women & $\geq 110 \mathrm{mg} \mathrm{dl}-1$ \\
Plasma glucose concentration &
\end{tabular}

aSystolic and diastolic blood pressure values were combined to represent one condition (hypertension as represented by SBP $\geq 130$ $\mathrm{mm} / \mathrm{Hg}$ and $\mathrm{DBP} \geq 85 \mathrm{~mm} / \mathrm{Hg}$ ).

Metabolic syndrome status was defined as meeting of three or more of the five criteria. gle block in order to determine whether PTSD severity was a valid predictor of metabolic syndrome status, while controlling for all other demographic, behavioral and psychiatric variables.

\section{Results \\ Participants}

Table 2 describes the sociodemographic, medical and psychiatric characteristics of participants. The sample was primarily male and white, with an average age of $52 \pm 9$ years. A large proportion served in the US Army and more than $70 \%$ served in Vietnam; $55 \%$ of the veterans met criteria for PTSD, as defined by a CAPS score of more than 65 and all met DSM-IV criteria for PTSD based on the presence of intrusion, avoidance and hyperarousal scores. There were 54 veterans $(21 \%)$ who did not meet criteria for PTSD based on the three DSM-IV symptom clusters and another 60 veterans (24\%) who had subthreshold PTSD (reported all three types of symptom, but had a total CAPS score less than 65). Close to two-thirds of the participants met criteria for MDD. Abuse or dependence of nicotine, alcohol and other substances were also prevalent in this sample. In addition, there was high comorbidity between PTSD and MDD, lifetime nicotine abuse or dependence, past substance abuse or dependence, and past alcohol abuse or dependence.

The overall prevalence of current metabolic syndrome in our sample was 39.9\%. Among those with PTSD only, $34.3 \%(n=12)$ met criteria for metabolic syndrome as compared with $28.8 \%(n=17)$ of those with MDD only. For those with PTSD and MDD, 46.2\% $(n=48)$ met criteria for metabolic syndrome. Mean values for physical and laboratory measures, shown in Table 3, indicate that, on average, the sample had elevated serum triglycerides, high total cholesterol/HDL ratios and central obesity. Group differences between those with and without PTSD on these physical and laboratory measures were not significant except for those with PTSD had significantly higher DBP measures than those without PTSD $(t=-2.15, p=$ $0.033)$. These multiple $t$-tests evaluating group differences were not corrected for possible inflation of Type I error (that is, the Bonferroni principle).

\section{PTSD and metabolic syndrome}

Table 4 presents the results of the logistic regression model used to predict presence of metabolic syndrome. The overall regression model produced an adequate model fit $(-2 \log$ likelihood $=316.650$, chi-squared $=$ $23.731, p=0.005)$. CAPS total score (Wald $=4.76, p=$ 0.03 , odds ratio $(\mathrm{OR})=1.01$ ) was a significant predictor of metabolic syndrome. Regression coefficients indicated that veterans' risk for metabolic syndrome increased one percentage point for each point obtained on the CAPS. Gender was also a significant, unique predictor of risk for metabolic syndrome with women having lower risk 
Table 2: Sociodemographic, medical and psychiatric characteristics of veterans $(N=253)$

\begin{tabular}{|c|c|}
\hline Sociodemographic data & Number (percentage) of all veterans \\
\hline Male & $233(92 \%)$ \\
\hline \multicolumn{2}{|l|}{ Race } \\
\hline White & 193 (76.3\%) \\
\hline Black & 47 (18.6\%) \\
\hline Other & $13(5.1 \%)$ \\
\hline \multicolumn{2}{|l|}{ Branch of service } \\
\hline Army & $153(60.5 \%)$ \\
\hline Marines & $53(20.9 \%)$ \\
\hline Navy & $26(10.3 \%)$ \\
\hline Air Force & $21(8.3 \%)$ \\
\hline \multicolumn{2}{|l|}{ Service era } \\
\hline World War II & $7(2.8 \%)$ \\
\hline Korea & $8(3.2 \%)$ \\
\hline Vietnam & 180 (7I.I\%) \\
\hline Gulf War I & $36(14.2 \%)$ \\
\hline Other conflicts & $22(8.7 \%)$ \\
\hline \multicolumn{2}{|l|}{ Medical and psychiatric diagnoses } \\
\hline \multicolumn{2}{|l|}{ PTSD } \\
\hline At least moderate severity & $139(54.9 \%)^{\mathrm{a}}$ \\
\hline Subthreshold severity & $60(24.0 \%)^{a}$ \\
\hline MDD & $163(64.4 \%)$ \\
\hline Nicotine abuse/dependence (lifetime) & $98(38.7 \%)$ \\
\hline Substance abuse/dependence (past) & $102(40.3 \%)$ \\
\hline Alcohol abuse/dependence (past) & $174(68.8 \%)$ \\
\hline Co-morbid PTSD and MDD & $104(41.1 \%)^{b}$ \\
\hline Co-morbid PTSD and lifetime nicotine abuse/dependence & $53(20.9 \%)$ \\
\hline Co-morbid PTSD and past substance abuse/dependence & $67(26.5 \%)$ \\
\hline Co-morbid PTSD and past alcohol abuse/dependence & $107(42.3 \%)$ \\
\hline Metabolic syndrome (prevalence) & $101(39.9 \%)^{c}$ \\
\hline PTSD only and metabolic syndrome & $12(34.3 \%)^{d}$ \\
\hline MDD only and metabolic syndrome & $17(28.8 \%)^{\mathrm{e}}$ \\
\hline PTSD, MDD and metabolic syndrome & $48(46.2 \%)^{f}$ \\
\hline \multicolumn{2}{|l|}{ Other factors: } \\
\hline \multicolumn{2}{|l|}{ Age $($ mean \pm standard deviation $(S D))=51.5 \pm 9.0$ years } \\
\hline \multicolumn{2}{|l|}{ Length of education (mean $\pm S D)=12.9 \pm 2.4$ years } \\
\hline CAPS score $($ mean \pm SD $)=62.8 \pm 29.4$ years. & \\
\hline
\end{tabular}

aThose identified as meeting Diagnostic and Statistical Manual of Mental Disorders, 4th Edition (DSM-IV) criteria for posttraumatic stress disorder (PTSD) were subclassified into subthreshold (Clinician Administered PTSD Scale (CAPS) < 65) or moderate to severe PTSD (CAPS $\geq 65$ ).

bDiagnosis of PTSD if CAPS $\geq 65$; diagnosis of major depressive disorder (MDD) determined by structured psychodiagnostic clinical interview. cMetabolic syndrome status if three of five criteria are present (serum triglycerides at least $150 \mathrm{mg} \mathrm{dl}^{-1}$, high-density lipoprotein less than $35 \mathrm{mg} \mathrm{dl}^{-}$ , blood pressure at least $130 / 85 \mathrm{~mm} / \mathrm{Hg}$, waist-to-hip ratio at least 0.90 for men and at least 0.85 for women, and plasma glucose concentration at least $\left.110 \mathrm{mg} \mathrm{dl}^{-1}\right)$.

dPercentage of those with PTSD only who meet criteria for metabolic syndrome. ePercentage of those with MDD only who meet criteria for metabolic syndrome.

fPercentage of those with both PTSD and MDD who meet criteria for metabolic syndrome.

(Wald $=4.852, p=0.028, \mathrm{OR}=0.17)$. To determine whether the comorbidity between PTSD and MDD in our sample $(41 \%)$ would introduce problems related to multicollinearity to our model, we conducted diagnostic tests (variance inflation factor (VIF) estimates and tolerance) and found no evidence for multicollinearity (VIF $=1.053$, tolerance $=0.950)$.

\section{Discussion}

In a sample of 253 male and female veterans, greater severity of PTSD was associated with higher likelihood of metabolic syndrome after controlling for relevant demo- graphic, behavioral and psychiatric factors. This finding aligns with and extends existing research examining metabolic syndrome in populations vulnerable to PTSD. Violanti and colleagues found metabolic syndrome to be three times more likely in police officers with severe PTSD symptoms as compared with police officers in the lowest PTSD severity category [33], while others have found that that $31-35 \%$ of male war veteran samples with combat PTSD evidenced concomitant metabolic syndrome $[34,35]$. Of note, the current study utilized the largest sample size to date and the most diverse in terms of gender, given the small but extant presence of women. 
Table 3: Physical measures and laboratory values used to determine metabolic syndrome

\begin{tabular}{|c|c|c|c|c|}
\hline Measures & All Veterans $(N=253)$ & With PTSD $(N=139)$ & Without PTSD $(N=1 \mid 4)$ & $p$ \\
\hline Serum triglycerides & $189.5 \pm 141.8$ & $194.6 \pm 154.7$ & $183.3 \pm 124.7$ & ns \\
\hline High-density lipoprotein & $42.7 \pm 11.3$ & $42.5 \pm 10.6$ & $43.0 \pm 12.0$ & ns \\
\hline \multicolumn{5}{|l|}{ Blood pressure } \\
\hline Systolic & $130.8 \pm 15.3$ & $132.2 \pm 16.0$ & $129.1 \pm 14.4$ & ns \\
\hline Diastolic & $81.7 \pm 10.0$ & $82.9 \pm 9.9$ & $80.2 \pm 10.0$ & 0.033 \\
\hline \multicolumn{5}{|l|}{ Waist-to-hip ratio } \\
\hline Men & $0.97 \pm 0.07$ & $0.98 \pm 0.07$ & $0.97 \pm 0.06$ & ns \\
\hline Women & $0.85 \pm 0.06$ & $0.87 \pm 0.03$ & $0.84 \pm 0.06$ & ns \\
\hline Plasma glucose concentration & $106.4 \pm 26.8$ & $105.6 \pm 26.3$ & $107.5 \pm 27.5$ & ns \\
\hline
\end{tabular}

All values are mean \pm standard deviation. Diagnosis of posttraumatic stress disorder (PTSD) if Clinician Administered PTSD Scale (CAPS) $\geq 65$ and Diagnostic and Statistical Manual of Mental Disorders, 4th Edition (DSM-IV) criteria for PTSD are met. ns, not significant.

The importance of the association between PTSD and metabolic syndrome becomes apparent when one considers the fact that metabolic syndrome has been shown to predict CVD-related morbidity and mortality $[23,25]$. Our findings suggest that metabolic syndrome provides a useful framework for assessing and describing the physiologic burden of PTSD and can be used prospectively to evaluate the increased health risk associated with combat exposure and PTSD.

The prevalence of metabolic syndrome in our sample (40\%) and specifically among those with PTSD (43\%) were slightly higher than rates observed among adults in the general population as reported in the National Health and Nutrition Examination Survey (NHANES) which ranged from $20 \%$ to $31 \%$ [36-38]. Loucks and colleagues reported mean values from men and women ages 25 years and over on individual metabolic syndrome components also collected in our sample (HDL, serum triglycerides, SBP, DBP, and fasting glucose) [36]. Compared with the women and men surveyed in NHANES, our sample of veterans tended to have higher mean triglycerides $(189.5 \mathrm{mg}$ $\mathrm{dl}^{-1}$ versus 132.3 and $164.0 \mathrm{mg} \mathrm{dl}^{-1}$ for women and men, respectively), higher SBP (130.8 mm/Hg versus 122.1 and
$123.1 \mathrm{~mm} / \mathrm{Hg})$, higher DBP $(81.7 \mathrm{~mm} / \mathrm{Hg}$ versus 71.2 and $74.4 \mathrm{~mm} / \mathrm{Hg})$, higher fasting glucose $\left(106.4 \mathrm{mg} \mathrm{dl}^{-1}\right.$ versus 98.8 and $103.4 \mathrm{mg} \mathrm{dl}^{-1}$ ), and lower HDL (42.7 mg $\mathrm{dl}^{-1}$ versus 55.8 and $45.3 \mathrm{mg} \mathrm{dl}^{-1}$ ). While our sample appeared to be 'less healthy' based on the pattern of mean values, our participants also tended to be older (mean age of 51.5 years as compared with mean ages of 47.2 and 44.7 years for women and men, respectively, in NHANES).

In spite of the growing attention on the importance and surveillance of metabolic syndrome, it should be noted that there is still considerable controversy regarding its definition and utility. Recent reviews pose questions regarding the need for a consensus in the definition of metabolic syndrome, lack of certainty about the underlying pathophysiological process, whether the syndrome itself conveys more information about health risk than the sum of its individual components, and how different combinations of risk factors should guide clinical management [39-41]. In addition to research examining longterm health risk from PTSD, prospective studies are similarly needed to continue to address these remaining questions about metabolic syndrome.

Table 4: Logistic regression predicting metabolic syndrome score

\begin{tabular}{|c|c|c|c|c|c|c|c|}
\hline \multirow[t]{2}{*}{ Variable } & \multirow[t]{2}{*}{ Estimate } & \multirow{2}{*}{ Standard error } & \multirow[t]{2}{*}{ Wald } & \multirow[t]{2}{*}{$P$} & \multirow[t]{2}{*}{ OR } & \multicolumn{2}{|c|}{$95 \% \mathrm{Cl}$} \\
\hline & & & & & & Lower & Upper \\
\hline Age & 0.032 & 0.017 & 3.710 & 0.054 & 1.033 & 0.999 & 1.068 \\
\hline Race & -0.329 & 0.324 & 1.031 & 0.310 & 0.719 & 0.381 & 1.358 \\
\hline Gender & -1.772 & 0.805 & 4.852 & 0.028 & 0.170 & 0.035 & 0.823 \\
\hline Years of education & 0.013 & 0.059 & 0.051 & 0.821 & 1.014 & 0.903 & 1.138 \\
\hline Nicotine abuse & -0.439 & 0.281 & 2.441 & 0.118 & 0.645 & 0.372 & 1.118 \\
\hline Substance abuse & 0.418 & 0.294 & 2.015 & 0.156 & 1.519 & 0.853 & 2.704 \\
\hline Alcohol abuse & -0.317 & 0.332 & 0.915 & 0.339 & 0.728 & 0.380 & 1.395 \\
\hline MDD & -0.274 & 0.293 & 0.876 & 0.349 & 0.760 & 0.429 & 1.349 \\
\hline CAPS & 0.011 & 0.005 & 4.759 & 0.029 & 1.011 & 1.001 & 1.022 \\
\hline
\end{tabular}

'Race' reflects the difference in metabolic risk comparing veterans of non-white to those of white ethnicity. MDD, major depressive disorder. 'CAPS' reflects one unit change in metabolic risk associated with one unit change in Clinician Administered PTSD Scale (CAPS) score. 
A closely related concept, allostatic load, represents the cumulative biological burden of exposure to repeated cycles of adaptation to stress [42]. It incorporates the notion of stress, as well as the contribution of genetic, developmental, and lifestyle factors that might underpin the physiologic response to daily life events and traumatic stressors [42-45]. The selected factors that contribute to metabolic syndrome in this study closely approximate the secondary mediators of allostatic load, with the exception of serum triglycerides $[46,47]$. Our cross-sectional findings show a relationship between PTSD and metabolic syndrome suggesting that perhaps metabolic syndrome in itself is a useful clinical tool in quantifying the cardiovascular and metabolic impact of PTSD. In comparing those with and without PTSD on individual measures of metabolic syndrome components, we only found significant group differences for DBP, suggesting the utility of considering these measures collectively as the presence or absence of metabolic syndrome. It should be noted, however, that these multiple comparisons were not adjusted according to the Bonferroni principle, thereby potentially inflating Type I error in our analysis. Several studies appear to support the dysregulating effect of PTSD on a number of physiologic systems [12-16,33-35,48]. Given this association, future prospective studies examining physical morbidity and mortality related to PTSD should also assess metabolic syndrome to determine whether the pattern of dysregulation represented by metabolic syndrome mediates long-term health risk in PTSD.

Interestingly, we did not find MDD to be a significant and unique predictor of risk for metabolic syndrome, in spite of preliminary findings suggesting increased HPA activity with depression [49-55]. These previous studies, however, focused on depression and did not assess or control for PTSD. Our findings may provide preliminary evidence for a higher relative contribution of PTSD to metabolic syndrome after controlling for MDD.

One limitation of the current study is the under-representation of women and minority groups. While female gender was found to be associated with decreased risk of metabolic syndrome, in spite of the small number of women in the study (7.9\%), race did not appear to have unique effects on metabolic syndrome. A more diverse sample may yield important information on whether the relationship between PTSD and metabolic syndrome is robust across different racial/ethnic groups.

Finally, given the cross-sectional design of our study, we cannot fully establish a causal relationship between PTSD and metabolic syndrome. Prospective studies are clearly needed in this area to fully examine the long-term health risk related to PTSD.

\section{Conclusion}

This study extends the current knowledge of PTSD and diminished health status by examining metabolic syndrome while controlling for relevant health and psychiatric variables. After controlling for MDD, and alcohol, nicotine and substance abuse or dependence, we found a robust and significant association between PTSD severity and health risk as measured by metabolic syndrome. Further exploration, using prospective studies with assessment of CVD- and metabolic-related conditions, are indicated to determine whether metabolic syndrome can sufficiently account for the higher morbidity and mortality observed among those exposed to trauma or with PTSD.

\section{Abbreviations}

CAPS: Clinician Administered PTSD Scale; CVD: cardiovascular disease; DBP: diastolic blood pressure; DSM-IV: Diagnostic and Statistical Manual of Mental Disorders, 4th Edition; HDL: high-density lipoprotein; HPA: hypothalamic-pituitary-adrenocortical axis; MDD: major depressive disorder; NCEP: National Cholesterol Education Program; NHANES: National Health and Nutrition Examination Survey; OR: odds ratio; PTSD: posttraumatic stress disorder; SBP: systolic blood pressure; SD: standard deviations; SPSS: Statistical Package for Social Sciences; VIF: variance inflation factor; WHO: World Health Organization; WHR: waist-to-hip ratio.

\section{Competing interests}

The authors declare that they have no competing interests.

\section{Authors' contributions}

PSH (1) conducted statistical analyses and participated in drafting the manuscript. EFC was involved with statistical analysis and writing the manuscript. UAH was involved in data collection and study execution. NA participated in interpretation of the findings, as well as manuscript drafting and editing. RLH participated in editing the manuscript. BAD was involved with data processing and analysis and database construction. PSH (2) participated in statistical analyses. SEN assisted with manuscript editing and formatting. DGB carried out study design, data gathering and participated in manuscript drafting and editing.

\section{Acknowledgements}

DGB and RLH are supported by VACO Research funds (VA Merit Review, VA-DOD, MIRECC, HSR\&D, and the Office of Environmental Hazards).

This work is supported in part by these funds. NA is supported in part by NIH ROIAR5I524. PSH (I), NA, DGB, RLH, and SEN are also supported by the VA Center of Excellence for Stress and Mental Health. We thank the clinicians at the Veterans Affairs of Cincinnati who participated in the collection of data and Laura Harder who provided assistance with manuscript formatting. 


\section{References}

I. Krause N, Shaw BA, Cairney J: A descriptive epidemiology of lifetime trauma and the physical health status of older adults. Psychol Aging 2004, 19:637-648.

2. Boscarino JA: Posttraumatic stress disorder and mortality among U.S. Army veterans $\mathbf{3 0}$ years after military service. Ann Epidemiol 2006, I 6:248-256.

3. Kimerling $R$, Calhoun KS: Somatic symptoms, social support, and treatment seeking among sexual assault victims. J Consult Clin Psychol 1994, 62:333-340.

4. Pizarro J, Silver RC, Prause J: Physical and mental health costs of traumatic war experiences among Civil War veterans. Arch Gen Psychiatry 2006, 63:193-200.

5. Vieweg WV, Julius DA, Fernandez A, Tassone DM, Narla SN, Pandurangi AK: Posttraumatic stress disorder in male military veterans with comorbid overweight and obesity: psychotropic, antihypertensive, and metabolic medications. Prim Care Companion J Clin Psychiatry 2006, 8:25-3I.

6. Kang HK, Bullman TA, Taylor JW: Risk of selected cardiovascular diseases and posttraumatic stress disorder among former World War II prisoners of war. Ann Epidemiol 2006, I 6:38I-386.

7. Boscarino JA: Posttraumatic stress disorder and physical illness: results from clinical and epidemiologic studies. Ann NY Acad Sci 2004, 1032: 14I-I53.

8. Maia DB, Marmar CR, Mendlowicz MV, Metzler T, Nobrega A, Peres MC, Coutinho ES, Volchan E, Figueira I: Abnormal serum lipid profile in Brazilian police officers with post-traumatic stress disorder. J Affect Disord 2008, I 07:259-263.

9. Vieweg WV, Julius DA, Bates J, Quinn JF 3rd, Fernandez A, Hasnain $\mathrm{M}$, Pandurangi AK: Posttraumatic stress disorder as a risk factor for obesity among male military veterans. Acta Psychiatr Scand 2007, I | 6:483-487.

10. Chrousos GP: Stressors, stress, and neuroendocrine integration of the adaptive response. The 1997 Hans Selye Memorial Lecture. Ann N Y Acad Sci 1998, 85 I:3। I-335.

II. Chrousos GP: Stress, chronic inflammation, and emotional and physical well-being: concurrent effects and chronic sequelae. J Allergy Clin Immunol 2000, I 06(Suppl):S275-S29I.

12. Baker DG, Geracioti TD, Kasckow JW, Zoumakis E, Chrousos GP: Cytokines and PTSD. In Cytokines and Mental Health Edited by: Kronfol Z Boston, MA: Kluwer Academic; 2003:301-338.

13. Baker DG, West SA, Nicholson WE, Ekhator NN, Kasckow JW, Hill KK, Bruce AB, Orth DN, Geracioti TD Jr: Serial CSF corticotropin-releasing hormone levels and adrenocortical activity in combat veterans with posttraumatic stress disorder. Am J Psychiatry 1999, 156:585-588.

14. Baker DG, Ekhator NN, Kasckow JW, Hill KK, Zoumakis E, Dashevsky BA, Chrousos GP, Geracioti TD Jr: Plasma and cerebrospinal fluid interleukin-6 concentrations in posttraumatic stress disorder. Neuroimmunomodulation 200I, 9:209-2I 7.

15. Bremner JD, Licinio J, Darnell A, Krystal JH, Owens MJ, Southwick SM, Nemeroff CB, Charney DS: Elevated CSF corticotropinreleasing factor concentrations in posttraumatic stress disorder. Am J Psychiatry 1997, I 54:624-629.

16. Geracioti TD Jr, Baker DG, Ekhator NN, West SA, Hill KK, Bruce AB, Schmidt D, Rounds-Kugler B, Yehuda R, Keck PE Jr, Kasckow JW: CSF norepinephrine concentrations in posttraumatic stress disorder. Am J Psychiatry 200 I, I 58: | 227-1230.

17. Grundy SM, Cleeman JI, Daniels SR, Donato KA, Eckel RH, Franklin BA, Gordon DJ, Krauss RM, Savage PJ, Smith SC Jr, Spertus JA, Costa $F$ : Diagnosis and management of the metabolic syndrome. An American Heart Association/National Heart, Lung, and Blood Institute Scientific Statement. Executive summary. Cardiol Rev 2005, 1 3:322-327.

18. Chrousos GP: The role of stress and the hypothalamic-pituitary-adrenal axis in the pathogenesis of the metabolic syndrome: neuro-endocrine and target tissue-related causes. Int J Obes Relat Metab Disord 2000, 24(Suppl 2):S50-S55.

19. Brunner EJ, Hemingway H, Walker BR, Page M, Clarke P, Juneja $M$, Shipley MJ, Kumari M, Andrew R, Seckl JR, et al.: Adrenocortical, autonomic, and inflammatory causes of the metabolic syndrome: nested case-control study. Circulation 2002, 1 06:2659-2665.

20. Chandola T, Brunner E, Marmot M: Chronic stress at work and the metabolic syndrome: prospective study. BMJ 2006, 332:52I-525.
21. Blanchard MS, Eisen SA, Alpern R, Karlinsky J, Toomey R, Reda DJ, Murphy FM, Jackson LW, Kang HK: Chronic multisymptom illness complex in Gulf War I veterans 10 years later. Am J Epidemiol 2006, I 63:66-75.

22. Pervanidou P, Kanaka-Gantenbein C, Chrousos GP: Assessment of metabolic profile in a clinical setting. Curr Opin Clin Nutr Metab Care 2006, 9:589-595.

23. Lakka HM, Laaksonen DE, Lakka TA, Niskanen LK, Kumpusalo E, Tuomilehto J, Salonen JT: The metabolic syndrome and total and cardiovascular disease mortality in middle-aged men. JAMA 2002, 288:2709-27I6.

24. Laaksonen DE, Lakka HM, Niskanen LK, Kaplan GA, Salonen JT, Lakka TA: Metabolic syndrome and development of diabetes mellitus: application and validation of recently suggested definitions of the metabolic syndrome in a prospective cohort study. Am J Epidemiol 2002, I 56:1070-1077.

25. Kohli $\mathrm{P}$, Greenland $\mathrm{P}$ : Role of the metabolic syndrome in risk assessment for coronary heart disease. JAMA 2006, 295:819-82I.

26. Blake DD, Weathers FW, Nagy LM, Kaloupek DG, Gusman FD, Charney DS, Keane TM: The development of a ClinicianAdministered PTSD Scale. J Trauma Stress 1995, 8:75-90.

27. Weathers FW, Ruscio AM, Keane TM: Psychometric properties of nine scoring rules for the Clinician-Administered Posttraumatic Stress Disorder Scale. Psychol Assess 1999, I I: 124-133.

28. First MB, Spitzer RL, Gibbon M, Williams JBW: Structured Clinical Interview for DSM-IV Axis I Disorders-Clinician Version (SCID-I) Washington, DC: American Psychiatric Press; 1997.

29. Smeets RMW, Dingemans PMAJ: Composite Internation Diagnostic Interview (CIDI)-Version I.I Amsterdam: World Health Organization; 1993.

30. Expert Panel on Detection, Evaluation, and Treatment of High Blood Cholesterol in Adults (Adult Treatment Panel III): Executive Summary of The Third Report of The National Cholesterol Education Program (NCEP). JAMA 200I, 285:2486-2497.

31. Alberti KG, Zimmet PZ: Definition, diagnosis and classification of diabetes mellitus and its complications. Part I: diagnosis and classification of diabetes mellitus provisional report of a WHO consultation. Diabet Med 1998, I 5:539-553.

32. World Health Organization: Definition, Diagnosis, and Classification of Diabetes Mellitus and its Complications, Part I. In Diagnosis and Classification of Diabetes Mellitus Geneva: World Health Organization; [Technical Report Series, No. 99.92.]; 1999.

33. Violanti JM, Fekedulegn D, Hartley TA, Andrew ME, Charles LE, Mnatsakanova A, Burchfiel CM: Police trauma and cardiovascular disease: association between PTSD symptoms and metabolic syndrome. Int J Emerg Ment Health 2006, 8:227-237.

34. Jakovljevic M, Saric M, Nad S, Topic R, Vuksan-Cusa B: Metabolic syndrome, somatic and psychiatric comorbidity in war veterans with post-traumatic stress disorder: preliminary findings. Psychiatr Danub 2006, I 8:169-I76.

35. Babic D, Jakovljevic M, Martinac M, Saric M, Topic R, Maslov B: Metabolic syndrome and combat post-traumatic stress disorder intensity: preliminary findings. Psychiatr Danub 2007, 19:68-75.

36. Loucks EB, Magnusson KT, Cook S, Rehkopf DH, Ford ES, Berkman LF: Socioeconomic position and the metabolic syndrome in early, middle, and late life: evidence from NHANES I9992002. Ann Epidemiol 2007, I 7:782-790.

37. Park YW, Zhu S, Palaniappan L, Heshka S, Carnethon MR, Heymsfield $\mathrm{SB}$ : The metabolic syndrome: prevalence and associated risk factor findings in the US population from the Third National Health and Nutrition Examination Survey, 1988-1994. Arch Intern Med 2003, I 63:427-436.

38. Ford ES, Giles WH, Dietz WH: Prevalence of the metabolic syndrome among US adults: findings from the third National Health and Nutrition Examination Survey. JAMA 2002, 287:356-359.

39. de Zeeuw D, Bakker SJ: Does the metabolic syndrome add to the diagnosis and treatment of cardiovascular disease? Nat Clin Pract Cardiovasc Med 2008, 5(SuppI I):SIO-SI4.

40. Brietzke SA: Controversy in diagnosis and management of the metabolic syndrome. Med Clin North Am 2007, 9 I: I04 I- I06 I. viiviii

4l. Kahn R, Buse J, Ferrannini E, Stern M: The metabolic syndrome: time for a critical appraisal: joint statement from the Amer- 
ican Diabetes Association and the European Association for the Study of Diabetes. Diabetes Care 2005, 28:2289-2304.

42. McEwen BS, Stellar E: Stress and the individual. Mechanisms leading to disease. Arch Intern Med 1993, 153:2093-2I0I.

43. McEwen BS: The neurobiology and neuroendocrinology of stress. Implications for post-traumatic stress disorder from a basic science perspective. Psychiatr Clin North Am 2002, 25:469-494. ix

44. McEwen BS: Protective and damaging effects of stress mediators. N Engl J Med 1998, 338:17|-I79.

45. McEwen BS: Allostasis and allostatic load: implications for neuropsychopharmacology. Neuropsychopharmacology 2000, 22:108-124.

46. Seeman TE, McEwen BS, Rowe JW, Singer BH: Allostatic load as a marker of cumulative biological risk: MacArthur studies of successful aging. Proc Natl Acad Sci USA 200I, 98:4770-4775.

47. Seeman TE, Singer BH, Rowe JW, Horwitz RI, McEwen BS: Price of adaptation - allostatic load and its health consequences. MacArthur studies of successful aging. Arch Intern Med 1997, I 57:2259-2268.

48. Glover DA, Stuber M, Poland RE: Allostatic load in women with and without PTSD symptoms. Psychiatry 2006, 69:19I-203.

49. Heiskanen TH, Niskanen LK, Hintikka J], Koivumaa-Honkanen HT, Honkalampi KM, Haatainen KM, Viinamaki HT: Metabolic syndrome and depression: a cross-sectional analysis. J Clin Psychiatry 2006, 67: | $422-1427$.

50. Sachar EJ, Hellman L, Fukushima DK, Gallagher TF: Cortisol production in depressive illness. A clinical and biochemical clarification. Arch Gen Psychiatry 1970, 23:289-298.

5I. Deuschle M, Blum WF, Strasburger CJ, Schweiger U, Weber B, Korner A, Standhardt H, Gotthardt U, Schmider J, Pflaum CD, et al.: Insulin-like growth factor-I (IGF-I) plasma concentrations are increased in depressed patients. Psychoneuroendocrinology 1997, 22:493-503.

52. Deuschle M, Weber B, Colla M, Depner M, Heuser I: Effects of major depression, aging and gender upon calculated diurnal free plasma cortisol concentrations: a re-evaluation study. Stress 1998, 2:28I-287.

53. Carroll BJ, Martin FI, Davies B: Resistance to suppression by dexamethasone of plasma II-O.H.C.S. levels in severe depressive illness. Br Med J 1968, 3:285-287.

54. Weber B, Lewicka S, Deuschle M, Colla M, Heuser I: Testosterone, androstenedione and dihydrotestosterone concentrations are elevated in female patients with major depression. Psychoneuroendocrinology 2000, 25:765-77।.

55. Young EA, Haskett RF, Grunhaus L, Pande A, Weinberg VM, Watson SJ, Akil H: Increased evening activation of the hypothalamicpituitary-adrenal axis in depressed patients. Arch Gen Psychiatry 1994, 5 I:701-707.

\section{Pre-publication history}

The pre-publication history for this paper can be accessed here:

\section{http://www.biomedcentral.com/1741-7015/7/1/prepub}

Publish with BioMed Central and every scientist can read your work free of charge

"BioMed Central will be the most significant development for disseminating the results of biomedical research in our lifetime. "

Sir Paul Nurse, Cancer Research UK

Your research papers will be:

- available free of charge to the entire biomedical community

- peer reviewed and published immediately upon acceptance

- cited in PubMed and archived on PubMed Central

- yours - you keep the copyright
BioMedcentral 